ГЕОЭКОЛОГИЯ

И РАЦИОНАЛЬНОЕ ПРИРОДОПОЛЬЗОВАНИЕ 


\title{
ОЦЕНКА СЛОЖНОСТИ ЛАНДШАФТНОЙ ОРГАНИЗАЦИИ ОХРАННЫХ ЗОН ОСТРОВА РУССКИЙ
}

\author{
Борисов Р.В. \\ Тихоокеанский институт географии ДВО РАН, Владивосток \\ ruslanbor93@gmail.com
}

\begin{abstract}
Аннотация. Остров Русский с недавнего времени активно внедряется в единую социально-экономическую сеть г. Владивостока. Проведение крупных строительных работ на острове может привести к коренной трансформации геосистем, в связи с чем формирование системы устойчивого развития приобретает особую актуальность. Важным этапом является анализ закономерностей ландшафтной организации и функционирования геосистем. Основное внимание в работе было уделено выделяемым согласно нормативно-правовым документам охранным зонам острова, для которых существуют ограничения хозяйственного использования. Нами была выполнена оценка сложности ландшафтной организации охранных зон о. Русский. Правовое экологическое зонирование острова позволило проанализировать пространственную структуру охранных зон, наибольшую площадь среди которых занимает водоохранная зона. Были рассмотрены особенности ландшафтной организации территории острова. Обработка данных дистанционного зондирования, цифровых моделей рельефа и анализ ландшафтной организации позволили определить ландшафтную структуру охранных зон. Анализ ландшафтной организации не включал в себя антропогенно преобразованные территории, к которым относятся земли объектов культурного наследия. Анализ особенностей пространственной структуры ландшафтов водоохранных зон озер, водотоков и моря был выполнен на основе количественных показателей. В сравнительных целях анализ осуществлялся также для ландшафтов не охраняемой территории. Расчет показателей ландшафтной структуры позволил выполнить анализ ландшафтной сложности и ландшафтного разнообразия охранных зон о. Русский. Выполненный в настоящей работе анализ сложности ландшафтного рисунка и ландшафтного разнообразия определяет территорию охранных зон как наиболее сложную и неоднородную по ландшафтной организации в сравнении с неохраняемой территорией острова. Оценка ландшафтной организации охранных зон о. Русский может быть использована в дальнейших исследованиях, направленных на формирование сбалансированной системы управления островной природно-хозяйственной системой.
\end{abstract}

Ключевые слова: остров Русский, охранные зоны, ландшафтная организация, ландшафтная сложность, ландшафтное разнообразие. 


\title{
ESTIMATION OF THE COMPLEXITY \\ OF THE LANDSCAPE ORGANIZATION OF PROTECTION AREAS OF THE RUSSKY ISLAND
}

\author{
Borisov R.V. \\ Pacific Geographical Institute FEB RAS, Vladivostok
}

\begin{abstract}
Annotation. Since recently, the Russky Island has been actively introduced into the single socio-economic network of the city of Vladivostok. Conducting large-scale construction work on the island can lead to a fundamental transformation of geosystems, due to which the formation of a sustainable development system is of particular relevance. An important stage is the analysis of patterns of landscape organization and functioning of geosystems. The focus of the work was on the protected zones of the island, which are allocated according to regulatory documents, for which there are restrictions on economic use. We have evaluated the difficulty of the landscape organization of protection areas of the Russky island. Legal ecological zoning of the island allowed to analyze the territorial structure of protected zones, the largest area among which is occupied by a water protection zone. The features of the landscape organization of the island territory were considered. Processing of remote sensing data, digital elevation models and analysis of landscape organization made it possible to determine the landscape structure of protection zones. The analysis of landscape organization did not include anthropogenically transformed territories, which include lands of cultural heritage objects. We have analyzed the quantitative indicators of the features of the spatial structure of landscapes of water protection zones of lakes, watercourses and the sea. For comparative purposes, the analysis was also carried out for landscapes of a non-protected area. The calculation of the indicators of the difficulty of the landscape structure made it possible to perform an analysis of the landscape difficulty and landscape diversity of the protected zones of the Russky island. The analysis of the difficulty of landscape structure and landscape diversity carried out in this work determines the territory of protected zones as the most complex and heterogeneous in landscape organization in comparison with the unprotected territory of the island. The assessment of the landscape organization of the protected zones of the Russky Island can be used in further studies aimed at creating a balanced management system for the island's natural-economic system.
\end{abstract}

Key words: Russky Island, protection areas, landscape organization, landscape complexity, landscape diversity.

Остров Русский расположен в заливе Петра Великого Японского моря и входит в состав Владивостокского городского округа. Площадь острова равна 99,7 км², это наиболее крупный из островов залива. Остров Русский ближе других расположен к материковой части г. Владивостока, в связи с чем его развитию уделяется особое внимание как на региональном, так и на федеральном уровнях. В рамках подготовки к саммиту АТЭС 2012 г. на острове был возведен комплекс гостиничных корпусов и конференц-центров, которые в настоящее 
время используются в качестве кампуса Дальневосточного федерального университета. Мост, связавший о. Русский с основной частью города, и дальнейшее строительство объектов инфраструктуры способствуют внедрению его в единую социально-экономическую сеть г. Владивостока. Дальнейшая реализация строительных работ может привести к коренной трансформации геосистем, в связи с чем особую актуальность приобретает подробный анализ закономерностей ландшафтной организации и функционирования геосистем, что является неотъемлемой составляющей программы устойчивого развития территории. Основное внимание в работе было уделено выделяемым согласно нормативно-правовым документам охранным зонам острова, для которых существуют законодательные ограничения хозяйственного использования территории.

Целью настоящего исследования является оценка сложности ландшафтной организации охранных зон о. Русский. В соответствии с поставленной целью был выполнен комплекс задач: осуществлен анализ территориальной структуры охранных зон; рассмотрены особенности ландшафтной организации острова; обработаны данные дистанционного зондирования (ДДЗ), цифровые модели рельефа (ЦМР) по охранным зонам; проанализирована ландшафтная структура охранных зон; произведен расчет показателей сложности ландшафтной структуры и ландшафтного разнообразия охранных зон о. Русский.

Нами использовались качественные и количественные методы исследования, ключевым из которых явился картографо-статистический. ДД3, представленные на сервере GoogleEarth, и данные ландшафтной организации [3] обрабатывались с использованием программного пакета ArcMap10.3. Количественный анализ ландшафтной структуры и ландшафтного разнообразия осуществлялся для охранных земель о. Русский. В работе использовались группы простейших показателей и показателей сложности ландшафтного рисунка (табл. 1) [4].

На о. Русский представлены Дальневосточные бореальные и суббореальные средне- и южнотаежные притихоокеанские ландшафты с характерной муссонной циркуляцией воздушных масс [5]. Сотрудниками ТИГ ДВО РАН были проведены исследования ландшафтной организации [2] и выполнено ландшафтное картографирование [3] острова. Вся территория острова относится к горному классу ландшафтов. На уровне подклассов ландшафтов проявляются особенности функционирования островной замкнутой геосистемы. Более 
Количественные приемы анализа ландшафтных карт [4]

\begin{tabular}{|c|c|c|}
\hline № п/п & Показатель & Обозначение/формула \\
\hline \multicolumn{3}{|c|}{ Группа простейших характеристик } \\
\hline 1 & Площадь района (зоны) & $\mathrm{S}$ \\
\hline 2 & Площадь одного ПТК в районе (зоне) & $\mathrm{S}_{\mathrm{i}}$ \\
\hline 3 & Количество ПТК & M \\
\hline 4 & Количество контуров & $\mathrm{n}$ \\
\hline 5 & Среднее количество контуров на 1 ПТК & $\mathrm{p}$ \\
\hline 6 & Средняя площадь ландшафтных контуров & $\mathrm{S}_{0}=\frac{s}{n}$ \\
\hline \multicolumn{3}{|c|}{ Группа характеристик сложности } \\
\hline 7 & Индекс дробности ландшафтных контуров & $\mathrm{k}=\frac{n}{s}$ \\
\hline 8 & Коэффициент сложности & $\mathrm{K}_{\text {слож }}=\frac{n}{\mathrm{SO}}$ \\
\hline 9 & $\begin{array}{l}\text { Энтропийная мера сложности ландшафтного } \\
\text { рисунка }\end{array}$ & $\mathrm{H}=-\sum_{i=1}^{m} \frac{S i}{S} \log _{2} \frac{S i}{S}$ \\
\hline 10 & Индекс Маргалефа & $Д_{\mathrm{mg}}=\frac{(M-1)}{\ln S}$ \\
\hline
\end{tabular}

$81 \%$ территории острова приходится на низкогорный подкласс, который преимущественно сформирован денудационными пологими и средней крутизны склонами. В условиях муссонного климата с количеством осадков более $800 \mathrm{mм} /$ год ландшафты характеризуются избыточным увлажнением. Ландшафты острова подразделяются на группы: автоморфные, гидроморфные и полугидроморфные. Доминантами выступают геосистемы склоновые денудационные пологие сложенные гранитами и гранитоидами широколиственные кленово-ясенево-ольхово-липовые кустарниково-разнотравные с лианами на буроземах типичных [2].

Правовое экологическое зонирование о. Русский [1] выделяет три категории охранных земель: водоохранная зона, особо охраняемые природные территории (ООПТ), а также территория объектов культурно-исторического наследия (ОКН). Согласно нормативно-правовым документам [7-9] на данных территориях запрещается любая деятельность, способная привести к нарушению целостности взятых за основу объектов. Наибольшую площадь охранных земель острова за- 
нимает водоохранная зона - 5350,48 га (53,7 \% территории острова). На земли ОКН приходится 196,01 га (2 \% территории острова). Наименьшие площади занимают земли ООПТ - 4,65 га (0,1 \% территории острова) [1]. На рисунке представлен фрагмент карты правового экологического зонирования на примере центральной части о. Русский.

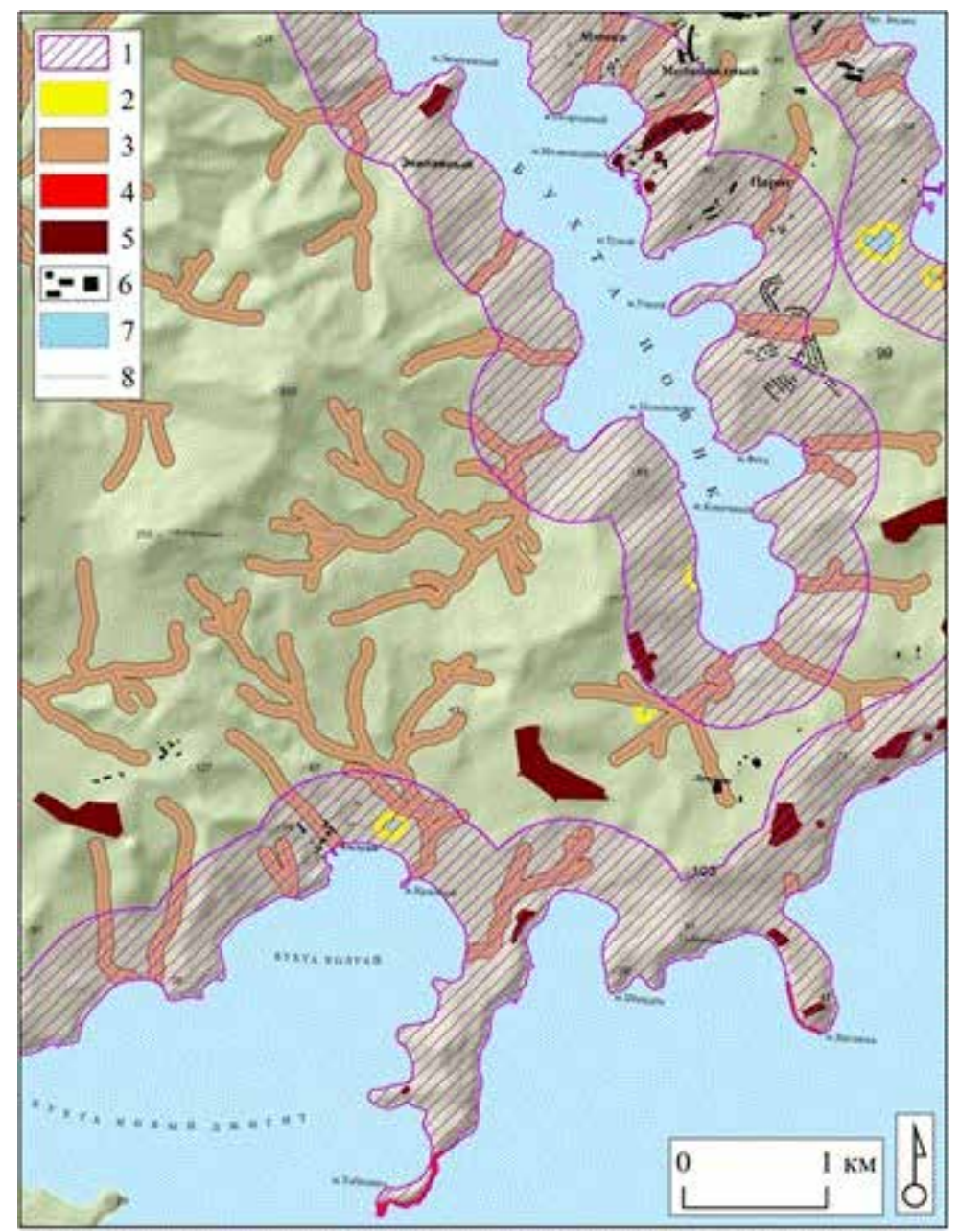

Рис. Фрагмент карты правового экологического зонирования о-ва Русский [1]

Условные обозначения: 1 - водоохранная зона моря; 2 - водоохранная зона озер; 3 водоохранная зона водотоков; 4 - ООПТ; 5 - ОКН; 6 - зона застроек; 7 - озера; 8 водотоки. 
Обработка ДДЗ, ЦМР и данных по ландшафтной организации позволила проанализировать ландшафтную организацию охранных зон о. Русский. Анализ ландшафтной организации не включал в себя антропогенно преобразованные территории, к которым относятся земли ОКН. ООПТ, на которые приходится менее $0,1 \%$ территории острова, расположены вдоль береговой линии, поэтому их земли были отнесены к водоохранной зоне моря. Нами был выполнен анализ особенностей пространственной структуры ландшафтов водоохранных зон озер, водотоков и моря на основе расчета показателей сложности ландшафтного рисунка и ландшафтного разнообразия. В сравнительных целях анализ осуществлялся также для ландшафтов неохраняемой территории.

На первом этапе был выполнен расчет простейших показателей ландшафтной структуры исследуемых территорий. Полученные данные послужили основой выполнения анализа ландшафтной сложности и ландшафтного разнообразия (табл. 2).

Охранные зоны о. Русский характеризуются более высоким показателем коэффициента сложности ландшафтного рисунка $(504,72)$, почти в пять раз превышающим показатель неохраняемой территории $(116,24)$. Максимальное значение по данному показателю приходится на водоохранную зону водотоков $(823,49)$, минимальное - на водоохранную зону озер (менее 62,3). Водоохранная зона озер отличается меньшей площадью, для которой характерна однородность ландшафтного строения.

Та блица 2

Количественные показатели ландшафтной структуры охранных зон о. Русский

\begin{tabular}{|c|c|c|c|c|c|}
\hline \multirow[b]{2}{*}{ Зона } & \multicolumn{5}{|c|}{ Группа простейших характеристик } \\
\hline & $\begin{array}{c}\text { Площадь, } \\
\text { кв.м(S) }\end{array}$ & $\begin{array}{c}\text { Количество } \\
\text { контуров } \\
\text { (n) }\end{array}$ & $\begin{array}{l}\text { Количе- } \\
\text { ство ПТК } \\
\text { (М) }\end{array}$ & $\begin{array}{c}\text { Среднее } \\
\text { количество } \\
\text { контуров на } \\
1 \text { ПТК (p) }\end{array}$ & $\begin{array}{c}\text { Средняя } \\
\text { площадь } \\
\text { ландшафтных } \\
\text { контуров }\left(\mathrm{S}_{0}\right)\end{array}$ \\
\hline $\begin{array}{l}\text { Водоохранная } \\
\text { зона }\end{array}$ & 4493,62 & 1506 & 218 & 6,91 & 2,98 \\
\hline озер & 26,98 & 41 & 26 & 1,58 & 0,66 \\
\hline водотоков & 955,41 & 887 & 131 & 6,77 & 1,08 \\
\hline моря & 3861,94 & 1077 & 203 & 5,31 & 3,59 \\
\hline $\begin{array}{l}\text { Не охраняемая } \\
\text { территория }\end{array}$ & 4312,43 & 708 & 134 & 5,28 & 6,09 \\
\hline
\end{tabular}


Окончание табл. 2

\begin{tabular}{|c|c|c|c|c|}
\hline \multirow[b]{2}{*}{ Зона } & \multicolumn{4}{|c|}{ Группа характеристик сложности } \\
\hline & $\begin{array}{c}\text { Индекс } \\
\text { дробности } \\
\text { ланд- } \\
\text { шафтных } \\
\text { контуров } \\
(\mathrm{k})\end{array}$ & $\begin{array}{c}\text { Коэф- } \\
\text { фициент } \\
\text { сложности } \\
\text { ландшафт- } \\
\text { ного рисун- } \\
\text { ка }\left(\mathrm{K}_{\text {слож }}\right)\end{array}$ & $\begin{array}{c}\text { Энтропий- } \\
\text { ная мера } \\
\text { сложно- } \\
\text { сти ланд- } \\
\text { шафтного } \\
\text { рисунка } \\
(\mathrm{H}) \\
\end{array}$ & Индекс Маргалефа (Д $\left.{ }_{\mathrm{mg}}\right)$ \\
\hline $\begin{array}{l}\text { Водоохранная } \\
\text { зона }\end{array}$ & 0,34 & 504,72 & 6,04 & 25,80 \\
\hline озер & 1,52 & 62,30 & 3,88 & 7,59 \\
\hline водотоков & 0,93 & 823,49 & 4,97 & 18,94 \\
\hline моря & 0,28 & 300,35 & 6,06 & 24,46 \\
\hline $\begin{array}{l}\text { Не охраняемая } \\
\text { территория }\end{array}$ & 0,16 & 116,24 & 3,67 & 15,89 \\
\hline
\end{tabular}

Показатель энтропийной сложности ландшафтного рисунка, отражающий вероятность смены одного ландшафта другим, также имеет наибольшее значение для охранных зон $(6,04)$. При этом максимальное значение данного показателя приходится на водоохранную зону моря $(6,06)$. Водоохранная зона озер также отличается наиболее низким показателем $(3,88)$.

Оценка природного разнообразия охранных зон осуществлялась нами с использованием методики Р. Маргалефа [6]. В настоящей работе под ландшафтным разнообразием понимается число и встречаемость ПТК на определенной территории. Расчет индекса Маргалефа сделал возможным определить степень ландшафтного разнообразия охранных зон и неохраняемой территории. Охранные зоны отличаются более высоким показателем индекса Маргалефа $(25,8)$ в сравнении с неохраняемой территорией $(15,89)$. Максимальное значение по данному показателю приходится на водоохранную зону моря $(24,46)$, минимальное - на водоохранную зону озер $(7,59)$.

Охранные зоны созданы с целью сохранения природного функционирования территории. Полученные данные свидетельствуют, что для охранных зон о. Русский характерна более высокая сложность и разнообразие ландшафтов. Из 236 выделяемых на острове ПТК [3] на охранные зоны приходится 218. Неохраняемая территория насчитывает 134 ПТК. На отличающиеся ландшафтной сложностью и разнообразием водоохранные зоны моря и водотоков приходится 203 и 131 
ПТК соответственно. Водоохранная зона водотоков играют важную роль в функционировании геосистем. Водотоки, представляя собой векторные геосистемы, играют ключевую роль в вещественно-энергетическом взаимодействии природных комплексов в ландшафтном катене. На основании полученных данных можно говорить также о высоком значении водоохранной зоны моря в функционировании единой островной природной системы.

Выполненный в настоящей работе анализ ландшафтной сложности и показателей ландшафтного разнообразия определяет территорию охранных зон как наиболее сложную и неоднородную по ландшафтной организации в сравнении с неохраняемой территорией о. Русский, несмотря на небольшие площадные различия. Оценка ландшафтной организации охранных зон может быть использована в дальнейших исследованиях, направленных на формирование сбалансированной системы управления островной природно-хозяйственной системой.

Работа выполнена при финансовой поддержке Российского научного фонда (проект 18-77-00001).

Научный руководитель: врио директора ТИГ ДВО РАН, к.г.н. Ганзей К.C.

\section{Литература}

1. Борисов Р.В. Правовое экологическое зонирование островов архипелага Императрицы Евгении // Успехи современного естествознания. 2019. № 3. С. 210-216.

2. Ганзей К.С., Киселева А.Г., Пшеничникова Н.Ф. Ландшафты острова Русский (залив Петра Великого, Японское море): пространственная организация и особенности функционирования // Успехи современного естествознания. 2016. № 6. С. 138-143.

3. Ганзей К.С., Киселева А.Г., Пшеничникова Н.Ф. Ландшафты острова Русский. Карта. Масштаб 1:25000. Владивосток: ООО «Колорит», 2016.

4. Викторов А.С. Рисунок ландшафта. М.: Мысль, 1986. 177 с.

5. Исаченко А.Г. Ландшафты СССР. Л.: Изд-во Ленингр. ун-та, 1985. 320 с.

6. Маргалеф Р. Облик биосферы. М.: Наука, 1992. 215 с.

7. Водный кодекс Российской Федерации от 3 июня 2006 г. N 74-Ф3 // Российская газета. 8 июня 2006 г. [Электронный ресурс]. - Режим доступа: https:// rg.ru/2006/06/08/voda-kodeks.html (дата обращения: 14.08.2019).

8. Федеральный закон «Об объектах культурного наследия (памятниках истории и культуры) народов Российской Федерации» от 25.06.2002 N 73-Ф3 (последняя редакция) // Официальный сайт компании «КонсультантПлюс» [Электронный ресурс]. - Режим доступа: http://www.consultant.ru/document/cons_doc_LAW_37318 (дата обращения: 14.08.2019). 
9. Федеральный закон «Об особо охраняемых природных территориях» от 14.03.1995 N 33-Ф3 (последняя редакция) // Официальный сайт компании «КонсультантПлюс» [Электронный ресурс]. - Режим доступа: http://www.consultant.ru/ document/cons_doc_LAW_6072 (дата обращения: 14.08.2019).

\section{References}

1. Borisov R.V. Pravovoye ekologicheskoye zonirovaniye ostrovov arkhipelaga Imperatritsy Yevgenii [Legal ecological zoning of the Islands of the Empress Eugenie archipelago]. Uspekhi sovremennogo yestestvoznaniya - Advances in current natural sciences, 2019, no. 3, pp. 210-216.

2. Ganzey K.S., Kiseleova A.G., Pshenichnikova N.F. Landshafty ostrova Russkiy (zaliv Petra Velikogo, Yaponskoye more): prostranstvennaya organizatsiya i osobennosti funktsionirovaniya [Landscapes of Russky Island (Peter the Great Bay, Sea of Japan): spatial organization and functioning peculiarities]. Uspekhi sovremennogo yestestvoznaniya - Advances in current natural sciences, 2016, no. 6, pp. 138-143.

3. Ganzey K.S., Kiseleova A.G., Pshenichnikova N.F. Landshafty ostrova Russkiy. Karta. Masshtab 1: 25000 [Landscapes of Russky Island. Map. Scale 1: 25000]. Vladivostok, 2016.

4. Viktorov A.S. Risunok landshafta [Landscape drawing]. Moscow, Mysl' Publ., 1986. $177 \mathrm{p}$.

5. Isachenko A.G. Landshafty SSSR [Landscapes of the USSR]. Leningrad, Leningrad St. Univ. Publ., 1985. 320 p.

6. Margalef R. Oblik biosfery [The shape of the biosphere]. Moscow, Nauka Publ., 1992. $215 \mathrm{p}$.

7. Federal'nyj zakon «Vodnyj kodeks Rossijskoj Federacii» ot 3 iyunya 2006 g. №74FZ [Russian Federation Federal Law «Water Code of the Russian Federation» of June 3, 2006 №74-FZ] // Rossiiskaia gazeta [Russian Newspaper], 2006, 8 June. Available at: https://rg.ru/2006/06/08/voda-kodeks.html (accessed 14.08.2019). (in Russian).

8. Federal'nyy zakon «Ob ob"yektakh kul'turnogo naslediya (pamyatnikakh istorii i kul'tury) narodov Rossiyskoy Federatsii» ot 25.06.2002 N 73-FZ (poslednyaya redaktsiya) [Federal Law «On Objects of Cultural Heritage (Monuments of History and Culture) of the Peoples of the Russian Federation» of June 25, 2002 N 73-FZ (last revised)]. Available at: http://www.consultant.ru/document/cons_doc_LAW_37318 (accessed 14.08.2019). (in Russian).

9. Federal'nyy zakon «Ob osobo okhranyayemykh prirodnykh territoriyakh» ot 14.03.1995 N 33-FZ (poslednyaya redaktsiya) [Federal Law «On Specially Protected Natural Territories» of 14.03.1995 N 33-FZ (last version)]. Available at: http://www. consultant.ru/document/cons_doc_LAW_6072 (accessed 14.08.2019). (in Russian). 